Research Article

\title{
Flexural Properties of Steel-Bamboo Composite Slabs in Different Connection Methods
}

\author{
Hui Zhong $\mathbb{D}^{1},{ }^{1}$ Qifeng Shan $\left(\mathbb{D},{ }^{1}\right.$ Jialiang Zhang, ${ }^{1}$ Xiaocun Zhang, ${ }^{1}$ and Yushun Li $\mathbb{D}^{2}$ \\ ${ }^{1}$ School of Civil and Environmental Engineering, Ningbo University, Ningbo 315211, China \\ ${ }^{2}$ College of Civil Engineering and Architecture, Qingdao Agricultural University, Qingdao 266109, China \\ Correspondence should be addressed to Yushun Li; lys0451@163.com
}

Received 5 October 2020; Revised 20 November 2020; Accepted 13 December 2020; Published 23 December 2020

Academic Editor: Dongsheng Huang

Copyright (c) 2020 Hui Zhong et al. This is an open access article distributed under the Creative Commons Attribution License, which permits unrestricted use, distribution, and reproduction in any medium, provided the original work is properly cited.

This paper presents a study aimed to estimate the flexural performance of profiled steel sheet-bamboo plywood composite slabs as a first step to evaluate its potential application as structural components. Nine specimens were tested to investigate the stability of steel-bamboo composite structure. According to different connection methods, three types of composite slabs were discussed, including pure bonding slabs (PBSs), composite bonding slabs (CBSs), and reinforced composite bonding slabs (RCBS). The result showed that specimens employed multiple composite methods (RCBS) exhibited excellent flexural bearing capacity and stiffness compared with PBS. The increase of bamboo plywood thickness could improve bearing capacity and flexural stiffness of composite slabs, while the reduction of screw spacing could enhance the bearing capacity and ductility of composite slabs. The RCBS, which can provide higher bearing capacity and stiffness and possess excellent deformation capability, are well worth of research and practical application.

\section{Introduction}

Today, environmental issues are receiving increasing attention because human activities have caused abnormal weather in many parts of the world. Construction industry, which is a huge source of carbon emissions and energy consumption, is facing the challenge of environmental protection. In order to maintain sustainable development of human society, it is essential to employ environmentfriendly materials as construction materials $[1,2]$. Bamboo has long been known for its fast growth, lightweight, high strength, and biodegradable properties. It is a kind of natural building material with the advantages of a large strength ratio and convenience of processing. However, the rigidity of bamboo plywood is insufficient and large deformation will occur when the load is applied $[3,4]$.

To have a better application of bamboo plywood in building structures, a new structural system named bamboo-steel composite structure was developed. This kind of structure consists of various composite members such as composite slab, composite wall, composite beam and composite column, with semirigid connection or other reliable connection methods [5-7]. Those structures combine the high strength of steel with the environmental amity of bamboo. Two materials are complementary to each other and bamboo plywood can avoid the weakness of easy buckling for profiled steel sheets. Buildings with those components are environmental friendly, light weight, and earthquake-resistant [8-11].

However, as a new structure system, researches on the steel-bamboo composite structure are rarely involved. Domestic and foreign researches focus on the composite structures like steel-concrete composite floor [12], steelwood structure [13], bamboo-concrete composite beams [14], CFRP, and wood structure [15]. Therefore, it is essential to investigate the properties of the steel-bamboo composite slabs.

In this study, a new type of bamboo-steel composite slab which consisted of four pieces of bamboo plywood and one piece of profiled steel sheet (Figure 1) was proposed. Adhesive bonding and adhesive-screw hybrid connection were utilized to form a whole component $[16,17]$. According to 


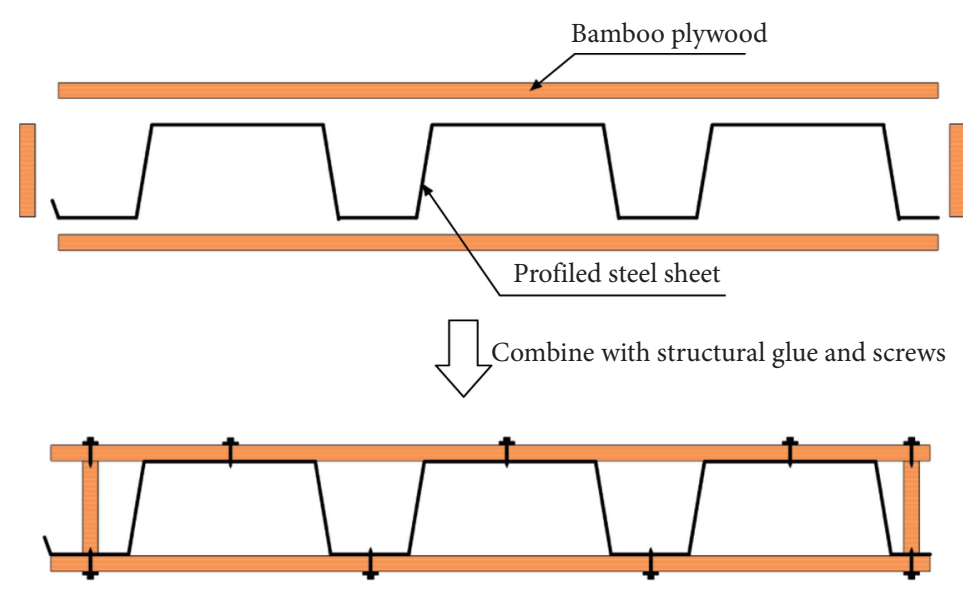

(a)

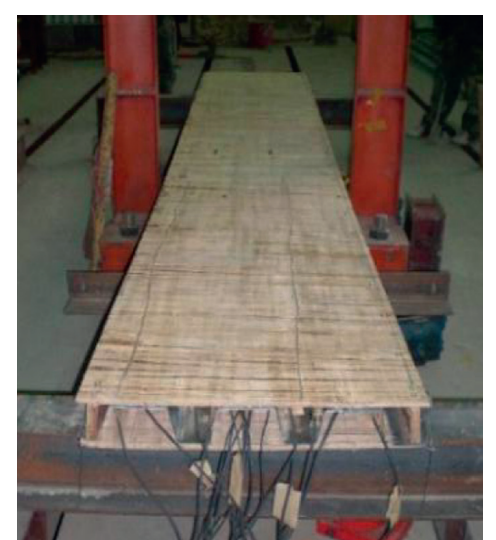

(b)

Figure 1: (a) Section form of composite slabs. (b) Photograph.

different connection methods, nine slab specimens were tested to investigate the mechanical properties of composite slabs and to discuss their application prospects.

\section{Specimens and Loading}

2.1. Specimens. Nine large-scale specimens were tested to investigate the mechanical properties of composite slabs. The dimension of these slab specimens is $0.65 \mathrm{~m} \times 3.3 \mathrm{~m}$ and the span is $3.0 \mathrm{~m}$. Three connection methods were adopted (Figure 2). One connection method named PBS was connected by simple adhesive bonding (Figure 2 (PBS)), and CBS was strengthened with the self-tapping screw on the basis of PBS (Figure 2 (CBS)). The last method is RCBS which improved capacity with bamboo laths nailed on both sides of the composite slab (Figure 2 (RCBS)). The first group, namely PBS, is designed as the control group. The difference between specimens in PBS is the thickness of bamboo plywood. The second group, CBS, is designed to investigate the function of screw and thickness of bamboo plywood as well. In the last group, RCBS, bamboo laths were utilized to compare with PBS and CBS. All parameters of these specimens are shown in Table 1. In addition, the section of a composite slab is hollow where it can be filled with various insulating piping, and the quality of this kind of composite floor is relatively light. In order to meet the requirements of practical applications, fine aggregate concrete of corresponding thickness can be laid on the floor to meet the seismic conditions. Thus, the vibration problem of composite slabs is not considered here.

\subsection{Material Properties}

2.2.1. Bamboo Plywood. As a new type of bamboo-based material, bamboo-based panel possess the advantages of high strength, low cost, and large dimensions with natural texture. The type of bamboo-based panel which is chosen for the composite slab is bamboo plywood. Raw bamboos are processed into a bamboo mat or bamboo curtain, and these crisscross group bamboo mats and curtains will be as the core material; after several processes including drying, dipping, lay-up and hot-press gluing, and the bamboo plywood was finally made. Typical thickness of bamboo plywood varies from $10 \mathrm{~mm}$ to $25 \mathrm{~mm}$, and this kind of bamboo plywood is massively produced and mainly used as concrete formwork in China and other Southeast Asian countries. In this experiment, the bamboo plywood is used as a component to prevent the profiled steel sheet from buckling. And in order to be used in practical engineering, the thickness of slabs should be thinner. Therefore, the thickness of bamboo plywood for composite specimens can be appropriately reduced and was chosen as $5 \mathrm{~mm}$, $6 \mathrm{~mm}$, and $7 \mathrm{~mm}$, respectively.

The average Young's modulus of bamboo plywood $\left(E_{b}\right)$ is shown in Table 2, which were obtained by conducting amounts of typical tests according to conventional testing methods for timber material. The detailed dimensions of the specimen are calculated by the following formula: $L=20 \times t+5(\mathrm{~mm}) . L$ is the length of bamboo plywood; $t$ is the thickness of bamboo plywood. The width of specimens is $50 \mathrm{~mm}$. And these tests were following the standard used in the U.S. (ASTM Standards: D4761). Figure 3(a) shows the typical tests to measure the modulus of elasticity (MOE) and modulus of rupture (MOR) of bamboo plywood. The loaddeflection curve of a typical specimen is shown in Figure 3(b). This curve showed a linear relationship to $0.8 \mathrm{kN}$, approximately $50 \%$ of the ultimate load. The result indicated that bamboo plywood has a strong deformation capacity.

2.2.2. Profiled Steel Sheet. The profiled steel sheet used coldrolled carbon constructional steel strip with a Young' modulus $\left(E_{s}\right)$ of $206 \mathrm{GPa}$, a yield strength $\left(f_{y}\right)$ of $235 \mathrm{MPa}$, a tensile strength $\left(f_{t}\right)$ of $375 \mathrm{MPa}$, and the thickness of the steel sheet adopted here is $0.75 \mathrm{~mm}$. It is a common coldformed thin-walled steel application to construction, such as concrete-steel composite structures (composite deck slabs) or light-weight steel construction (light-weight walls). The dimension details of profiled steel sheets are shown in Figure 4. 


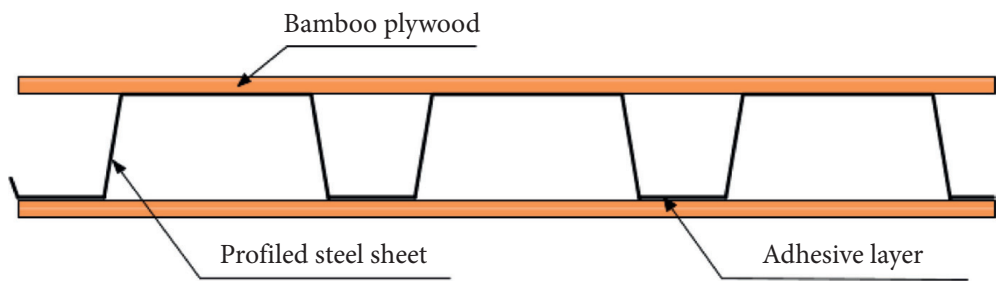

(a)

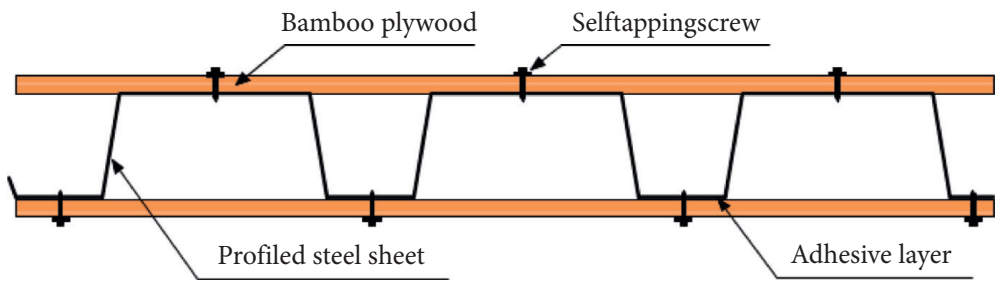

(b)

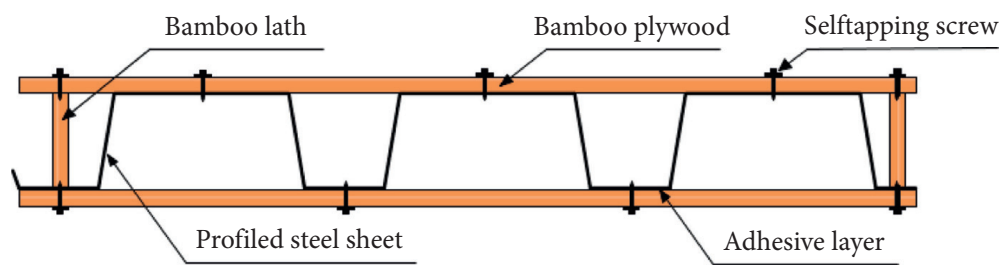

(c)

FIgure 2: Methods of connection. (a) PBS. (b) CBS. (c) RCBS.

TABLE 1: Detail of test specimens.

\begin{tabular}{|c|c|c|c|c|c|}
\hline Specimens & $t_{b}(\mathrm{~mm})$ & $t_{s}(\mathrm{~mm})$ & $h_{a}(\mathrm{~mm})$ & Screws spacing $(\mathrm{mm})$ & Span $(\mathrm{m})$ \\
\hline PBS-5 & 5.0 & 0.75 & 85.4 & - & 3.0 \\
\hline PBS-6 & 6.0 & 0.75 & 87.4 & - & 3.0 \\
\hline PBS-7 & 7.0 & 0.75 & 89.4 & - & 3.0 \\
\hline CBS-5 & 5.0 & 0.75 & 86.0 & 200,200 & 3.0 \\
\hline CBS-6 & 6.0 & 0.75 & 87.8 & 200,200 & 3.0 \\
\hline CBS-7 & 7.0 & 0.75 & 89.2 & 200,200 & 3.0 \\
\hline RCBS-7-1 & 7.0 & 0.75 & 89.4 & 200,400 & 3.0 \\
\hline RCBS-7-2 & 7.0 & 0.75 & 89.4 & 200,200 & 3.0 \\
\hline RCBS-7-3 & 7.0 & 0.75 & 89.4 & $200 / 100,200$ & 3.0 \\
\hline
\end{tabular}

Note. The height of profiled steel sheet is $75 \mathrm{~mm} . t_{b}$ is the thickness of bamboo plywood; $t_{s}$ is the thickness of profiled steel sheet; $h_{a}$ is the height of composite slab; selftapping screws spacing, A, B, and C: A is the uniform spacing on top bamboo plywood, B is the close-set spacing on top bamboo plywood in dense zone, and $\mathrm{C}$ is the uniform spacing on bottom bamboo plywood. The screw spacing of a lateral plate is the same as the bamboo plywood.

TABLE 2: Material properties.

\begin{tabular}{lc}
\hline Parameter & Value $(\mathrm{MPa})$ \\
\hline$E_{b}$ & 5885 \\
$E_{s}$ & 206 \\
$f_{y}$ & 235 \\
$f_{t}$ & 375 \\
\hline
\end{tabular}

Note. $E_{b}$ is the Young's modulus of bamboo plywood; $E_{s}$ is the Young' modulus of profiled steel sheet; $f_{y}$ is the yield strength of profiled steel sheet; $f_{t}$ is the tensile strength profiled steel sheet.

2.2.3. Adhesive Bonding and Selftapping Screw. In the experiment, two connection methods were adopted: adhesive bonding and selftapping screw. Among them, adhesive bonding is used to connect the surface between the bamboo plywood and the profiled steel sheet while selftapping screw is used for local reinforcement. The adhesive bonding used is called National Adhesives, which are produced and supplied by Henkel [18]. This adhesive is a common structural epoxy used for bonding metal, wood, glass, concrete, and others, with the advantage of rapid curing and high strength. And the selftapping screw used is common and efficient for coldformed steel structures with a nominal diameter of $4.5 \mathrm{~mm}$. The mechanical properties of this kind of adhesive and selftapping screw had been tested in previous experiments, and the shear strength and shear modulus of this structural adhesive were $5.1 \mathrm{MPa}$ and $0.25 \mathrm{GPa}$. [19].

2.3. Specimens Preparation. The specimens processing can be divided into four steps in total: (1) wiring and gluing. (2) Assembling. (3) Screwing. (4) Heavy object compaction (Figure 5). Before processing and preparing these composite 


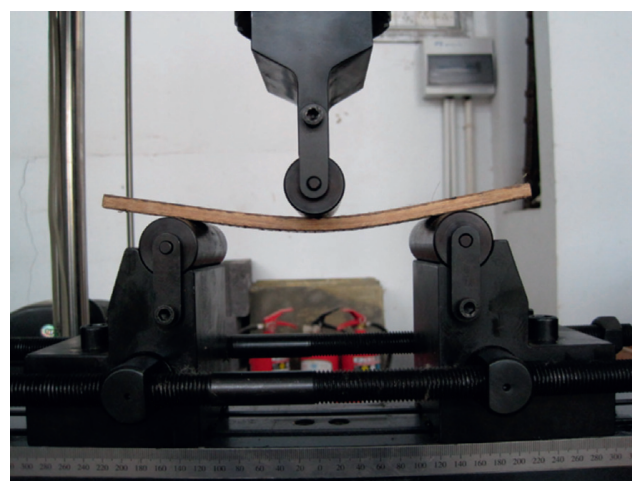

(a)

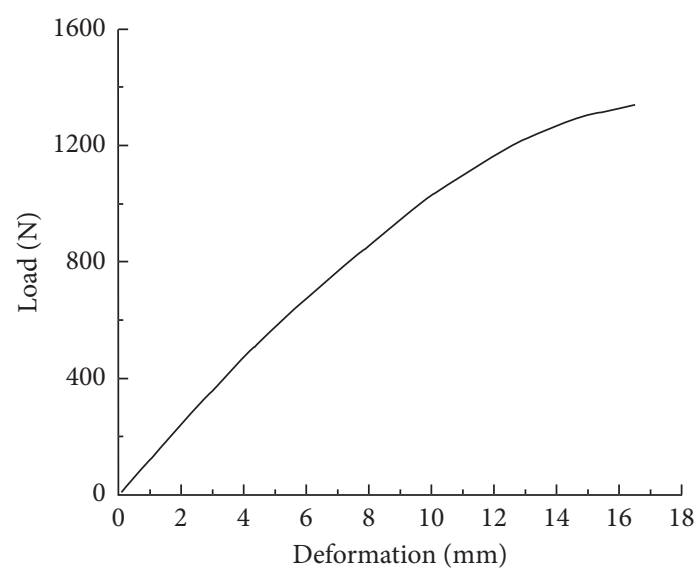

(b)

Figure 3: (a) Typical test for bamboo plywood. (b) Load-deformation curve of specimens.

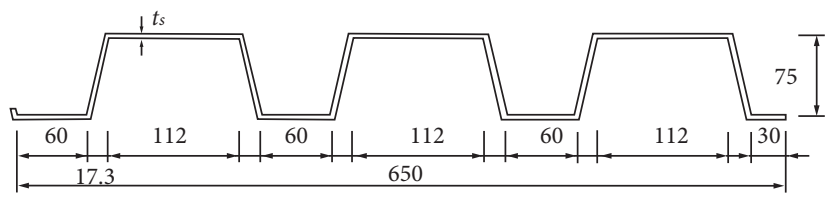

FIgURE 4: Dimension details of profiled steel sheet.

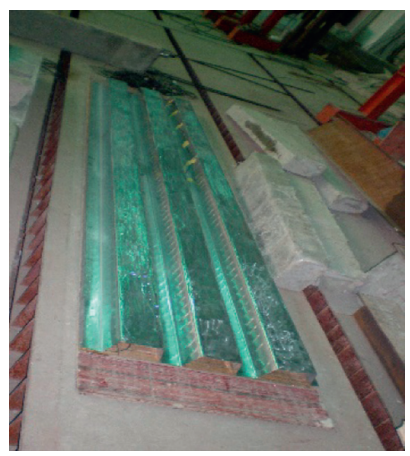

(a)

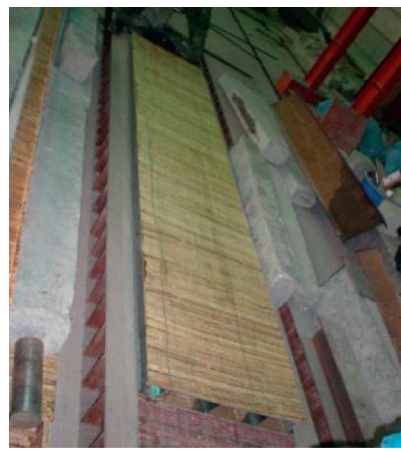

(b)

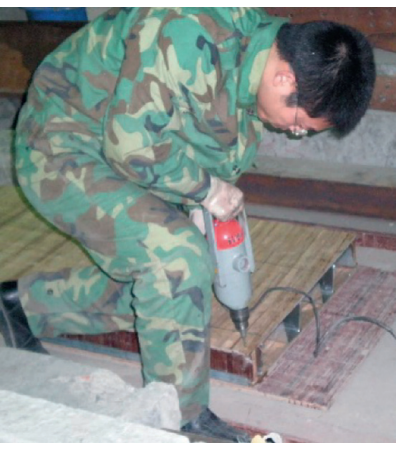

(c)

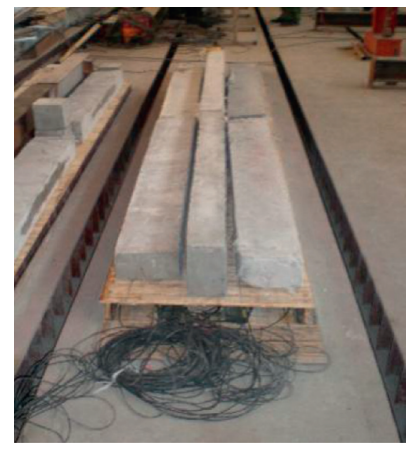

(d)

Figure 5: Specimens processing. (a) Wiring and gluing. (b) Assembling. (c) Screwing. (d) Compaction.

slabs, it is necessary to do surface treatments for the bamboo plywood and profiled steel sheet, which could remove impurities on the surface of the material and guarantee their connection effect. These specimens which used structure adhesive need pressure and curing, and the pressure period is two days, and the curing period is a week.

\subsection{Test Specimens and Set-Up. All the tests were carried out} in the Civil Engineering laboratories at Ningbo University and Northeast Forestry University. A Jack was used to control load and simulate the uniformly distributed load by means of eight points with four concentrated force. The width of the load application engaged the entire width of bamboo plywood. And strain gauges with a sampling frequency of $2 \mathrm{~Hz}$ were used to detect the stress-strain distribution of profiled steel sheet and bamboo plywood in the middle and a quarter of the slabs, respectively. Several displacement sensors were arranged to record the deformation of these specimens. Figure 6 shows the positions of strain gauges. Figure 7 shows the schematic representation of eight-point bending test.

\section{Experimental Result}

3.1. Failure Modes and Test Observations. Typical failure processes of composite slabs are shown in Figure 8, respectively.

Those bamboo-steel composite slabs have similar failure processes during the experiment, and all of the failure processes can be divided into three stages. Among them, the failure process of PBS is typical. During the first stage, the sound of crack can be heard and the initial crack can be observed on the connection surface of the slab. In the second 


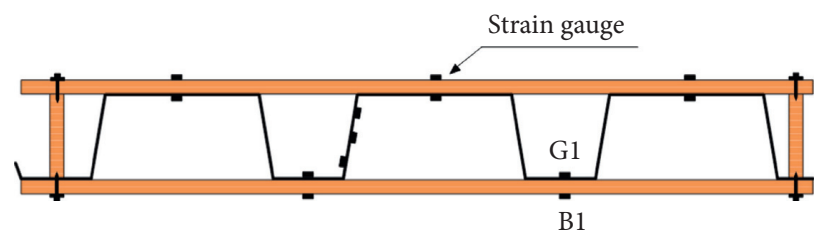

Figure 6: The positions of strain gauges.

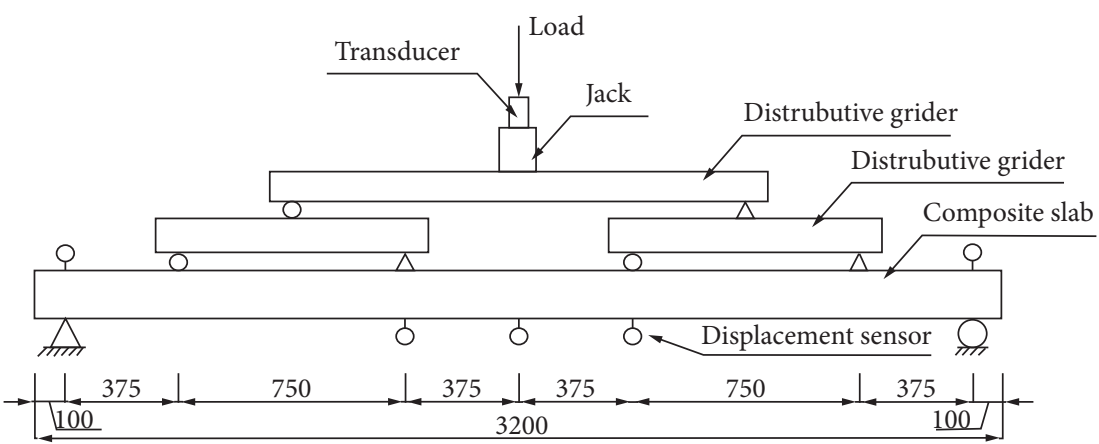

(a)

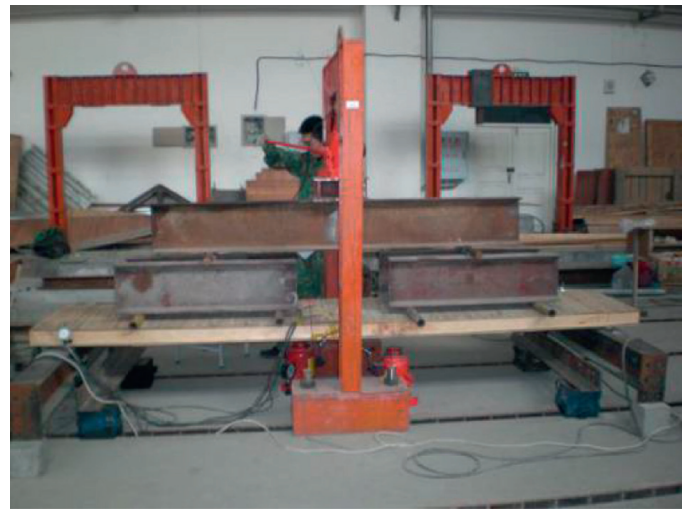

(b)

Figure 7: Eight points bending test. (a) Diagrammatic view. (b) Photograph.

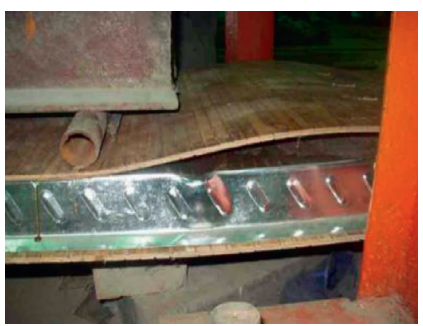

(a)

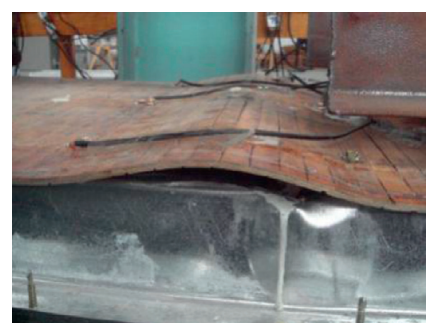

(b)

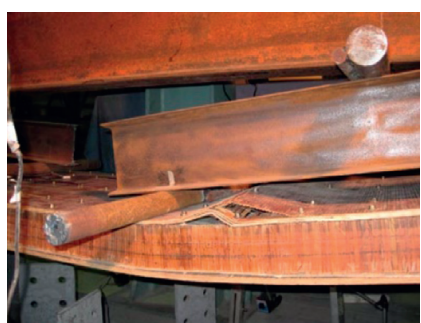

(c)

FIgURE 8: Failure mode of composite slabs. (a) Failure mode of PBS. (b) Failure mode of CBS. (c) Failure mode of RCBS.

stage, new cracks continued to exist and original cracks gradually widened. Most of the cracks were located at the upper surface of the slabs where they are close to the loading point. When the structural adhesive was fully damaged, the last stage had reached. Two materials were obviously separated, and the profiled steel sheet was locally buckled in the compression zones of the midspan section.
CBS and RCBS had the same failure processes as PBS during the first stage and second stage. In the last stage, in addition to the failure characteristics of PBS, a different phenomenon was visible as well. Screws of CBS were loosed, and the profiled steel sheet was locally buckled after the bamboo plywood between the screws gradually bulged. As for RCBS, the lateral slab was significantly deformed and the 
bamboo plywood at the screw connection was turn off before the profiled steel sheet was locally buckled. At the end of the test, local buckling as well as bending failure of longitudinal slab were observed.

3.2. Load-Deflection Curves and Bearing Capacity. The load vs. midspan deflection curves of specimens are shown in Figure 8, which are divided into three types according to different connection methods.

The curves of CBS were mainly linear up to the peak load, and then, the curves dropped suddenly. By looking at the curve shape of PBS and RCBS, it can be found that both have gone through the elastic stage, the plastic stage, and the descending stage. This suggests that they have similar ductility. However, it is evident that RCBS had a significant increase in bearing capacity. For example, the ultimate capacity of RCBS-7-2 was about four times higher than PBS7. All of the RCBS was linear up to $21 \mathrm{kN}$, which were approximately $88 \%, 70 \%$, and $74 \%$ of their peak load, respectively. Meanwhile, the deformation of this type specimen was considerably large. The maximum midspan deflection of RCBS-7-2 reached $59 \mathrm{~mm}$ measured by displacement sensor (Figure 9(c)). However, for those composite slabs, the maximum loads on serviceability limit states $\left(q_{n}\right)$ were much less than the ultimate ones $\left(q_{u}\right)$. For example, $q_{n}$ of RCBS-7-3 $(10 \mathrm{kN})$ was much smaller than $q_{u}$ $(28.35 \mathrm{kN})$. By comparing the theoretical bearing capacity with the experimental results, it can be concluded that the bearing capacity $\left(q_{n}\right)$ mainly depends on the original material properties of the bamboo plywood or profiled steel plate, not the reinforcement method. Of course, it is no doubt that these reinforced ways can improve the whole stability of composite slabs.

A summary of the experimental results is presented in Table 3 .

\section{Experimental Analysis}

4.1. Result Analysis. From the above, PBS, which used adhesive bonding only, is easy to cause adhesive failures. Once the profiled steel sheet and the bamboo plywood are separated, the bamboo plywood will produce a larger deflection which breaks the connection of steel and bamboo, resulting in the local buckling of the profiled steel sheet finally. Therefore, PBS is not suitable to exert the bearing capacity of the composite structure. CBS can avoid largescale adhesive failure, but the stiffness of them $\left(S_{w}\right)$ are significantly larger than PBS and RCBS. Destruction of these specimens began with the debonding of the bamboo plywood between the screws, then the screw connection failed quickly, and finally led to the buckle of the profiled steel sheet. As for RCBS, their ultimate bearing capacity and overall stability are significantly enhanced. In the failure experiment, the bamboo plywood cracked before the nails was pulled out, then the bamboo board came unglued, and eventually the whole board failed. Therefore, we can draw the conclusion that the property of bamboo plywood has been brought into full play. Comparing with the former two methods, RCBS can effectively improve the ductility of the composite slabs and is more conducive to the application of engineering.

4.2. Parametric Study. We adopted three connection modes to analyze the reliability and practicability of the bamboosteel composite slabs. The results indicated that the mechanical properties of RCBS were better than PBS and CBS. Meanwhile, parameters such as the thickness of bamboo plywood and the spacing of self-tapping screws may also cause differences in the ultimate bearing capacity.

4.2.1. Effect of Bamboo Plywood Thickness. A variety of different thickness of bamboo plywood were used in this experiment. In general, as the thickness of bamboo plywood increased, the ultimate bearing capacity of the composite slab improved. In the first group, with the increasing of the bamboo plywood thickness, the maximum load of the composite slab has been increased (Figure 9(a)). However, in the second group, under the effect of the screws, the variation in the thickness of the bamboo slab has little effect on mechanical performance.

4.2.2. Effect of Selftapping Screw Spacing. The specimens with selftapping screws can enhance the integrity of composite plates. For RCBS-7-1, its screw spacing is $200 / 400 \mathrm{~mm}$ and ultimate bearing capacity is $23.81 \mathrm{kN}$. The screw spacing of RCBS-7-2 is $200 \mathrm{~mm}$, and its ultimate bearing capacity is $29.82 \mathrm{kN}$. By changing the screw spacing of the bottom bamboo plywood, the ultimate bearing capacity is increased by $25 \%$. On the other hand, the connections between the steel sheet and bamboo plywood have also been improved. Taking RCBS-7-2 as an example, two strain gauges G1 and B1 were arranged at the bottom of its midspan slab (Figure 6) to draw its load-strain curve. By observing the curve (Figure 10), it can be found that the strain changes of the two strain gauges have high consistency, indicating that the combination effect between the steel sheet and bamboo plywood is obvious. Therefore, after adding screws, the connection between the bamboo plywood and the profiled steel sheet is much more stable, and the toughness and overall bearing capacity of the specimens are improved. Moreover, in the steel-bamboo structure, bamboo plywood was often more easily broken than screw joint when they are strengthened with screws, so it can be known that adding screws can thoroughly play the performance of bamboo plywood. In the experiment, screws arranged with a spacing of $200 \mathrm{~mm}$ can satisfy the strengthening of steel-bamboo structure. If the more denser spacing is adopted, local stiffness will be too large, thus reducing the overall strength and ductility.

4.2.3. Bamboo Lateral Slab. It is very effective to use lateral slabs to improve the ultimate bearing capacity and overall stability of bamboo-steel composite slabs. RCBS-7-2 attained ultimate bearing capacities of $29.82 \mathrm{kN}$, which are much higher than that of other specimens (Figure 11). Meanwhile, 


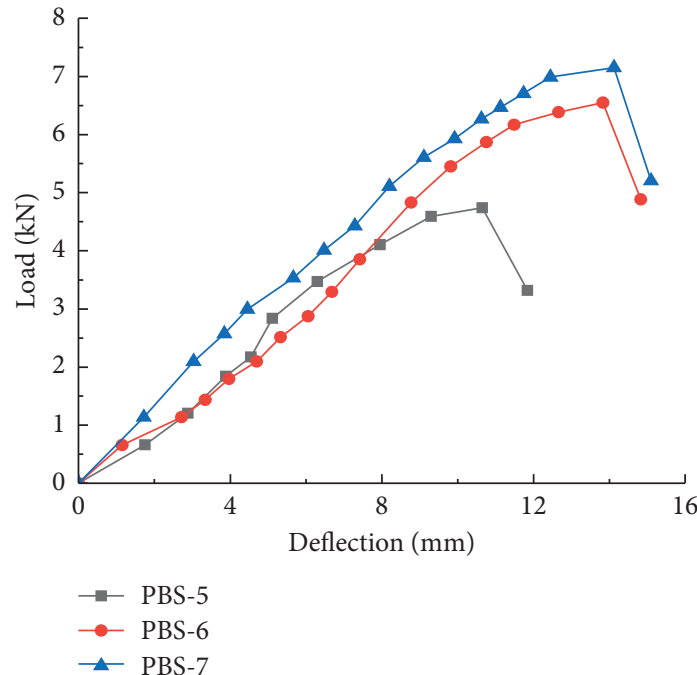

(a)

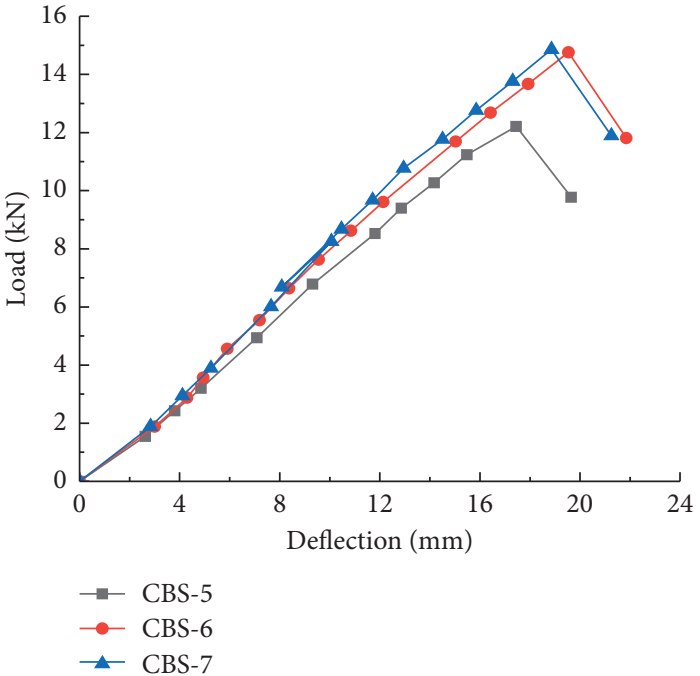

(b)

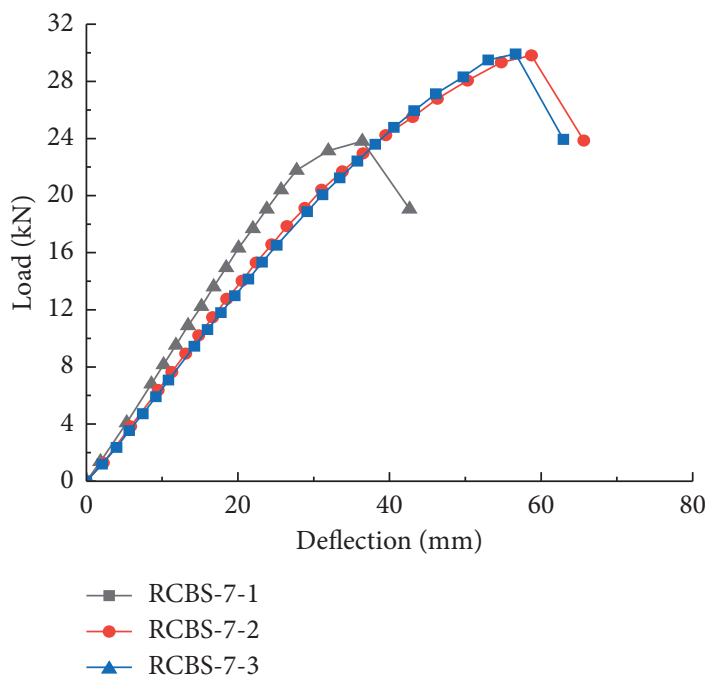

(c)

Figure 9: Load-deflection curves for bamboo-steel composite slabs. (a) Load-deflection curves for PBS. (b) Load-deflection curves for CBS. (c) Load-deflection curves for RCBS.

TABLE 3: Test results of large-scale specimens.

\begin{tabular}{lcccc}
\hline Specimens & Screws spacing $(\mathrm{mm})$ & $q_{u}(\mathrm{kN})$ & $f_{c \max }(\mathrm{mm})$ & 10.65 \\
\hline PBS-5 & - & 4.74 & 13.83 & $S_{w}(\mathrm{kN} / \mathrm{mm})$ \\
PBS-6 & - & 6.55 & 14.12 & 0.44 \\
PBS-7 & - & 7.16 & 17.48 & 0.47 \\
CBS-5 & 200,200 & 12.21 & 19.54 & 0.51 \\
CBS-6 & 200,200 & 14.76 & 18.86 & 0.70 \\
CBS-7 & 200,200 & 14.86 & 36.41 & 0.76 \\
RCBS-7-1 & 200,400 & 23.81 & 58.74 & 0.65 \\
RCBS-7-2 & 200,200 & 29.82 & 56.65 & 0.51 \\
RCBS-7-3 & $200 / 100,200$ & 28.35 & 0.50 \\
\hline
\end{tabular}

Note. $q_{u}$ is the ultimate load on bamboo-steel composite slab; $f_{c \max }$ is the maximum midspan deflection of bamboo-steel composite slab; $S_{w}$ is stiffness per unit.

the maximum deformation capacity of these specimens has been greatly improved. Taking RCBS-7-2 as an example, it has a maximum deformation of $58.74 \mathrm{~mm}$, which is much larger than the other specimens (Figure 12(a)). Therefore, the bamboo lath used can help these composite slabs to play better ductility and have good seismic performance as well. 


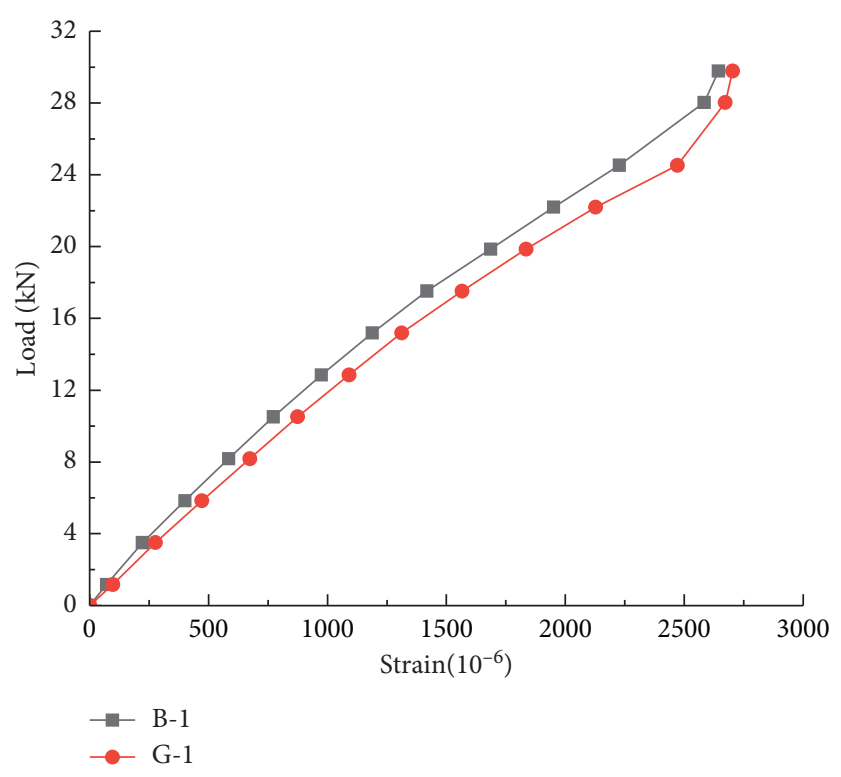

Figure 10: Load-strain curve of B-1 and G-1.

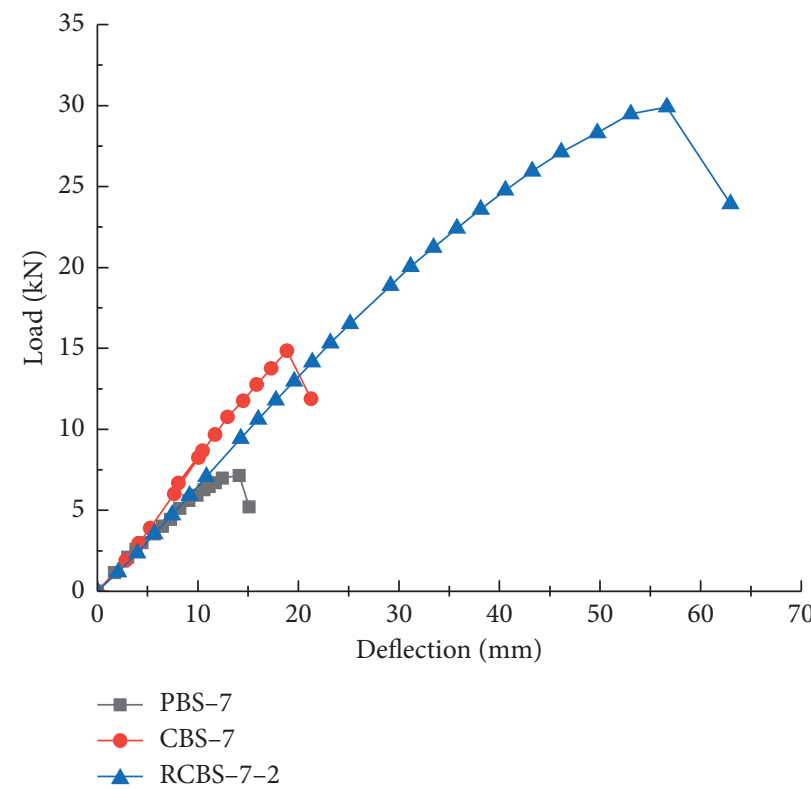

Figure 11: Comparison of composite slabs with different reinforcement methods.

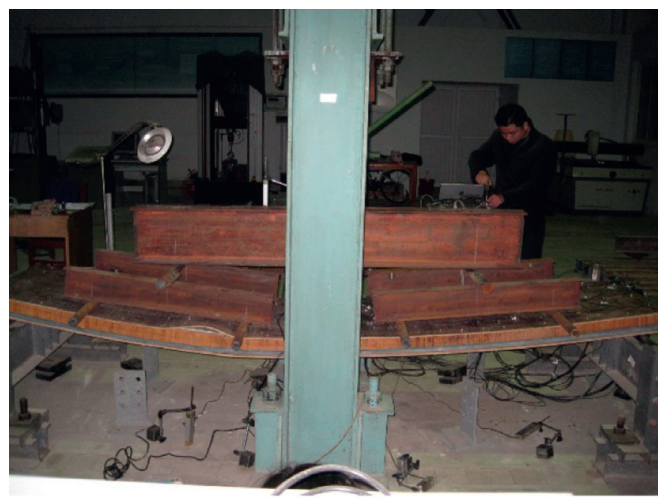

(a)

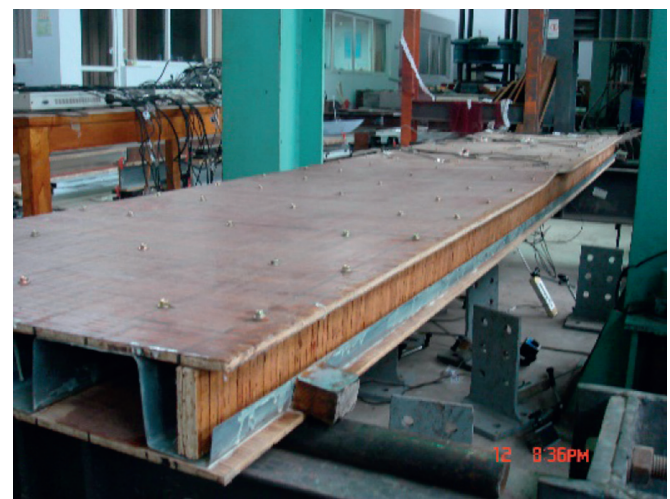

(b)

FIGURE 12: Deformation changes of RCBS. (a) Large deformation failure. (b) Recoverable deformation. 
What's more, by comparing the picture before and after deformation (Figure 12(b)), we can draw the conclusion that RCBS have a better ability to recover deformation. This is because the deformation of those specimens is mainly elastic deformation, which can be recovered quickly after unloading. Meanwhile, the residual deformation was very small which ensures that the composite floor can withstand repeated loads without any damage in actual work.

\section{Conclusion}

The present study is an attempt to investigate the possibility of combination between bamboo-based panels and profiled steel sheets with adhesives or adhesive-screw mixing connections to be slab floor. Based on the experimental results of nine composite slab specimens, the following can be concluded:

(1) The failure of composite floor is caused due to the invalidation of steel and bamboo connection. PBS and $\mathrm{CBS}$ are prone to connection failure because once they enter the plastic stage, their connections will quickly fail. Pure adhesive bonding is hard to provide good connection ability to the interface of bamboo plywood and profiled steel sheet. Even though CBS is enhanced with selftapping screws, the connection is not stable enough to prevent the separation of the whole component.

(2) The bearing capacity of RCBS is much better and they are ductile in the plastic deformation stage which is essential in practical application. This kind of composite slabs, with the advantage of simplicity, effectiveness, and economy, can make it the most industrially viable. The bamboo plywood side plate can effectively enhance the integrity of the composite floor and make the composite floor show ductility. Therefore, it is suggested that the composite floor should adopt the section form which is strengthened with a bamboo lateral slab.

(3) With the thickness of bamboo plywood increasing, the ultimate bearing capacity of composite slab improves obviously. In order to improve the performance of composite slab, it is important to choose a suitable thickness of bamboo plywood. Although adopting thicker bamboo plywood or steel sheets is beneficial for composite structure, its contribution to the whole bearing capacity is limited comparing with the connection method. Therefore, the thickness requirements can be met by using bamboo plywood and steel plates produced by ordinary processing.

(4) The screw spacing had an obvious influence on the bearing capacity and ductility of the composite structure. In the case of RCBS, the ultimate bearing capacities improve significantly when the screw spacing ranges between $200 \mathrm{~mm}$ and $400 \mathrm{~mm}$. However, as for CBS, the ultimate bearing capacities do not enhance markedly when the screw spacing ranges between $100 \mathrm{~mm}$ and $200 \mathrm{~mm}$. But the ductility of the specimen can be improved to some extent.

\section{Data Availability}

The data used to support the findings of this study are available from the corresponding author upon request.

\section{Conflicts of Interest}

The authors declare that there are no conflicts of interest regarding the publication of this paper.

\section{Acknowledgments}

The authors gratefully acknowledge the financial support provided by the National Natural Science Foundation of China (NSFC) (51678310 and 51978345), Ningbo Science and Technology Project (202002N3090), and Ningbo Natural Science Foundation (2018A610349). The acknowledgment is also extended to technical support of Civil Engineering Laboratories of Ningbo University and Northeast Forestry University.

\section{References}

[1] A. T. Balasbaneh, A. K. B. Marsono, and E. K. Kermanshahi, "Balancing of life cycle carbon and cost appraisal on alternative wall and roof design verification for residential building," Construction Innovation, vol. 18, no. 3, pp. 274-300, 2018.

[2] S. Paudel, S. Couturier, P. H. Nguyen, R. Kamphuis, B. Lacarrière, and O. Le Corre, "A relevant data selection method for energy consumption prediction of low energy building based on support vector machine," Energy and Buildings, vol. 138, pp. 240-256, 2017.

[3] M. Mahdavi, P. L. Clouston, and S. R. Arwade, "Development of laminated bamboo lumber: review of processing, performance, and economical considerations," Journal of Materials in Civil Engineering, vol. 23, no. 7, pp. 1036-1042, 2011.

[4] H. T. Li, Q. s. Zhang, D. S. Huang, and A. J. Deeks, "Compressive performance of laminated bamboo," Composites Part B: Engineering, vol. 54, pp. 319-328, 2013.

[5] S. Wei, Y. Li, H. Shen, and T. Jiang, "Tests and analysis on flexural strength of lightweight bamboo-steel composite floor slab," in Proceedings of the International Conference on Electric Technology \& Civil Engineering, Lushan, China, April 2011.

[6] Y. Li, S. Wei, Z. Huang, B. Ge, and W. Yan, "Experimental study on mechanical behavior of profiled steel sheet-bamboo plywood composite slabs," Jianzhu Jiegou Xuebao/Journal of Building Structures, vol. 29, no. 1, pp. 96-102, 2008.

[7] Y. Xiao, B. Shan, R. Z. Yang, Z. Li, and J. Chen, "Glue laminated bamboo (GluBam) for structural applications," Materials and Joints in Timber Structures, vol. 9, no. 1, pp. 589-601, 2014.

[8] J. Guo, Y. Li, B. Yang, and Y. Fei, "Study on the design of steelbamboo composite member," Applied Mechanics and Materials, vol. 204-208, pp. 4047-4050, 2012.

[9] Y. Wei, M. Q. Zhou, and D. J. Chen, "Flexural behaviour of glulam bamboo beams reinforced with near-surface mounted steel bars," Materials Research Innovations, vol. 19, no. 1, pp. 98-103, 2015.

[10] P. Lacki, P. Kasza, and K. Adamus, "Optimization of composite dowels shape in steel-concrete composite floor," Composite Structures, vol. 222, Article ID 110902, 2019. 
[11] T. V. P. Caldeira, N. Dourado, M. F. S. F. de Moura, and J. J. L. Morais, "Quasi-static behavior of moment-carrying steel-wood doweled joints," Construction and Building Materials, vol. 53, pp. 439-447, 2014.

[12] X. Zhou, Y. He, Z. Jia, and S. Nie, "Experimental study on vibration behavior of cold-form steel concrete composite floor," Advanced Steel Construction, vol. 7, no. 3, pp. 302-312, 2011.

[13] L. Zheng, M. He, F. Lam, R. Zhou, and M. Li, "Seismic reliability evaluation of steel-timber hybrid shear wall systems," Earthquakes and Structures, vol. 13, no. 3, pp. 289-297, 2017.

[14] B. Liu, W. L. S. Zhang, and Y. Xiao, "Mechanical behavior of connections for glubam-concrete composite beams," Construction and Building Materials, vol. 143, pp. 158-168, 2017.

[15] Q. F. Xie, J. Y. Xue, H. T. Zhao, and J. F. Hu, "Experimental study on bond behavior between CFRP sheet and wood," Advanced Materials Research, vol. 368-373, pp. 2314-2318, 2011.

[16] Y. S. Yu, W. L. He, and L. J. Li, "Optimal design of the mechanical properties of bamboo plywood form based on response surface model," Beijing Linye Daxue Xuebao/Journal of Beijing Forestry University, vol. 31, no. 7, p. 103, 2009.

[17] H. Y. Shen, Y. S. Li, W. L. Zhang, J. Xu, and B. Lü, "Experimental study on flexural behavior of cold-formed thinwall steel-bamboo plywood composite beams," Jianzhu Jiegou Xuebao/Journal of Building Structures, vol. 30, no. 5, p. 171, 2009.

[18] M. North, "Sticking to composites," Reinforced Plastics, vol. 51, no. 4, p. 32, 2007.

[19] J. Zhang, Z. Zhang, K. Tong, J. M. Wang, and Y. Li, "Bond performance of adhesively bonding interface of steel-bamboo composite structure," Journal of Renewable Materials, vol. 8, no. 6 , pp. $687-702,2020$. 